\title{
Los tres motores de la teoría social de Marx*
}

Esteban Torres*

Como en ningún otro momento en la historia, la recuperación y la actualización del proyecto moderno de Marx se convierte en

* Una versión preliminar de este texto fue presentada en inglés como ponencia en el Kongress MARX 200. Politik-Theorie-Socialismus, organizado por la Fundación Rosa Luxemburgo (Berlín, Alemania) entre los días 2 y 6 mayo de 2018. Luego, con posterioridad, una versión más avanzada fue publicado en inglés en la revista inglesa Critique. ("The Three Engines in Marx's Social Theory: Towards a Renewal of the Left". Critique. Vol 46. Issue 4, 2018. pp. 529-540). Aquí respetamos la primera parte del título de la segunda versión.

** Co-coordinador del Grupo de Trabajo de CLACSO "Teoría Social y realidad latinoamericana". Doctor por la Universidad Nacional de la Plata/Universidad Autónoma de Barcelona. Investigador del CONICET. Profesor adjunto a cargo de la Cátedra "Sociología", de la Escuela de Historia de la Universidad Nacional de Córdoba (UNC), Argentina, y de la Cátedra "Teorías y procesos de cambio social", de la Facultad de Ciencias Sociales, UNC. Su último libro publicado es: Hacia la renovación de la teoría social latinoamericana. Buenos Aires: CLACSO, 2020 (ed). 
una condición sine qua non para la renovación de la izquierda y el progresismo a nivel mundial. Tal exigencia de renovación se produce en un momento de retracción y de desconcierto generalizado frente a la expansión inédita de los programas neoliberales en el mundo entero. En el trabajo demostraré como la apuesta que subyace a este par de afirmaciones difiere radicalmente del típico y recurrente llamado marxista a retornar a Marx, un llamado que desde hace décadas las ciencias sociales no atienden.

El proyecto moderno de Marx queda perfectamente comprendido en la noción de identidad marxiana. Entiendo a esta identidad como un componente dinámico que se define a partir de la propia forma que adquiere la práctica de Marx como un todo. La práctica marxiana, a su vez, es una práctica general que contempla y enlaza una práctica teórica y una práctica política. Pese al volumen inconmensurable de discusiones que acumula el marxismo a lo largo de más de un siglo, llama la atención que la interrogación respecto al modo en que ambas prácticas se combinan haya sido poco explorada.

Tal como la entiendo, la práctica teórica marxiana se compone de tres núcleos o motores irreductibles entre sí y relacionados de modo inmanente: un motor racional-científico, un motor crítico y un motor transformativo. Esta distinción parte de considerar y de expandir la ecuación metodológica general que el propio Marx sugiere en el prólogo del Tomo I de El Capital. Allí el sociólogo señala que la dialéctica es a la vez "racional, crítica y revolucionaria" (Marx, 2011, p. 12). Apoyándome en el conjunto de su obra sostendré que la identidad marxiana es una identidad dialéctica, del mismo modo que es la propia dialéctica la que 
define su principio de identidad. Ahora bien, he podido constatar que tal identidad es dialéctica en un doble registro: en el movimiento desatado entre la práctica teórica y la práctica política, y luego al interior de la propia práctica teórica.

La dialéctica al interior de la teoría opera en primera instancia ligando los tres núcleos mencionados: el racional-científico, el crítico y el transformativo. Esta interpenetración permite registrar, entre otras cuestiones, la forma y la dimensión que adquiere la política al interior de la teoría, siendo tal registro, como luego veremos, comandado por el núcleo racional-científico. El doble movimiento mencionado se conforma a su vez en una cadena de mediaciones que involucra al conjunto del entramado socio-histórico en el cual se inscribe la trayectoria vital del sociólogo. El proyecto moderno de Marx, tal como lo entiendo a partir de su recomposición identitaria, se podría concebir como una fuerza socio-científica orientada a la transformación social. Cada una de las pequeñas y grandes soluciones dialécticas aportadas por el autor se convierte en un contrapunto y en una pista sustantiva para explicar el extravío y el fracaso de la Última Izquierda, al menos en América Latina.

\section{La motorización triádica de la práctica teórica}

Si bien en las últimas dos décadas se registran esfuerzos por develar el proceso de teorización social de Marx, en general se tiende a ofrecer una apreciación reduccionista respecto al modo en que funcionan e interactúan lo teórico-científico, lo crítico y lo transformativo en su práctica teórica. Hay autores que se limitan 
a reconocer la existencia de un único motor en la teoría de $\mathrm{Marx}^{2}$, otros que aluden a un esquema de dos motores ${ }^{3}$ y, luego, hay al-

2 Un caso destacado de reduccionismo uni-motor lo ofrece Slavoj Žižek. El intelectual esloveno reconoce que tanto el marxismo como el psicoanálisis "no solo son dos teorías acerca de la lucha, sino que son teorías luchadoras, comprometidas en una lucha" (Žižek, 2008, p. 11). De este modo, rescata exclusivamente la concreción teórica de una de las tres formas que componen el motor transformativo de la práctica marxiana: la forma-activación (ver punto 4 del texto). Otra visión uni-motor es la de Ignacio Lewcowicz. Para el historiador argentino el proyecto marxiano no integra una analítica de la sociedad y una estrategia de subjetivación, o bien una teoría de la historia y una teoría de la revolución, sino uno u otro de dichos elementos (Lewcowicz, 2000, p. 1). Otro caso de apropiación uni-motor del legado marxiano lo ofrece Jaques Bidet. Al sostener que el marxismo no es una religión sino una ciencia social moderna (Bidet, 2005, p. 8), el intelectual francés rescatará preferentemente el motor científico de la teoría marxiana.

3 Se pueden observar apropiaciones bi-motoras de la práctica teórica marxiana en autores marxistas como Terry Eagleton, Alain Badiou y Michael Burawoy, entre otros. Eagleton dirá que "el marxismo es mucho más que un método crítico, es una práctica política" (Eagleton, en Ríos y Díaz, 2013, p. 39). En su idea de "método crítico" queda contenido en motor científico y el motor crítico. El motor ausente en la visión del intelectual inglés es el motor transformativo, que alude a los componentes político y proyectivo de la teoría (ver Eagleton, 2011). La conceptualización que ofrece Badiou del legado marxiano también recae en una visión bi-motor, pero su definición es más compleja y cambiante. En 2007, el filósofo francés dirá que la práctica teórica marxiana es un "conocimiento organizado de los medios políticos requeridos para deshacer la sociedad existente y desplegar una figura por fin igualitaria y racional de la organización colectiva, cuyo nombre es "comunismo"" 
(Badiou, 2007, p. 14). Tal afirmación excluye el motor crítico a la vez que minimiza el motor científico. Respecto a esta última operación, $\mathrm{Ba}-$ diou no advierte al lector que tal conocimiento orientado políticamente se regula a partir de una teoría sociológica con pretensiones científicas. Estas falencias las subsana parcialmente años después. En 2012 el autor reconoce la existencia de tres Marx distintos. El Marx científico, relacionado con la crítica de la economía política; el Marx filósofo, propulsor del materialismo dialéctico; y, finalmente, el Marx militante político, que indica lo que hay que hacer para poder concretar la Idea Comunista. En esta clasificación Badiou opta por diferenciar entre ciencia y dialéctica, elementos que por su nivel de interdependencia quedan contenidos en el motor científico marxiano. La solución ideada por el filósofo francés en este punto se aproxima a su esquema anterior. En ambas Badiou termina anulando la especificidad y la autonomía del motor crítico a partir de subsumirlo a la lógica de producción de conocimiento metódico. Junto a ello, una vez presentados sus tres Marx, Badiou elige uno de ellos: “el Marx que a mí más me interesa, incluso reconociendo el mérito inmenso de todos los Marx, es el Marx que intenta ligar la idea comunista en su pureza ideológica y filosófica a las circunstancias concretas" (Badiou, en Febbro, 2012). De este modo, junto con la quita de especificidad del componente de la crítica, Badiou fracciona el proyecto intelectual de Marx al romper la lógica de articulación que enlaza tales elementos. El problema crítico es que Badiou presenta tal operación divisionista bajo un discurso de continuidad y no de ruptura con el legado marxiano. De este modo, es posible observar que tanto la conceptualización de Eagleton como la de Badiou registran una supeditación del componente teórico-científico al componente político. En el caso de Burawoy es a la inversa: el elemento que prima es el científico. El sociólogo norteamericano dirá que "el marxismo es una tradición analíticamente poderosa de la teoría social, de vital importancia para comprender científicamente los dilemas y posibilidades de cambio y 
gunos pocos autores que logran identificar los tres motores del movimiento teórico marxiano. Ahora bien, entre éstos últimos, el registro tiende a ser parcial y en gran medida desatento respecto a las formas de relacionamiento y de retroalimentación que hacen posible la combustión que enciende el dispositivo moderno de Marx $^{4}$.

de reproducción social en la sociedad contemporánea" (Burawoy y Olin Wright, 2000, p. 4; ver similar en Burawoy, 2003). De este modo, en la visión de los tres autores comentados se reconoce la primacía de uno de los motores sobre el restante. Luego hay autores que no fijan primacía alguna. Ésta última posición suele ir acompañada de la ausencia de reflexión respecto a la relación existente entre los motores intervinientes. Lo que se genera es un discurso de cohabitación no relacionada entre dos motores. La conceptualización que ofrece Marcello Musto es un buen ejemplo de esta última modalidad. El politólogo italiano dirá que los Marx indispensables son dos: el de la crítica al modo de producción capitalista y el teórico del socialismo (Musto, 2012, p. 14). Además de descomponer el proyecto de Marx, vemos como Musto quita de su definición la especificidad científica de la práctica marxiana. Esta nota al pie puede pasar al cuerpo del texto ya que es muy extensa, pero sobre todo necesaria.

4 Uno de los intelectuales que detectan la conformación tri-motora de la teoría social de Marx es Erik Olin Wright. El sociólogo norteamericano está dispuesto a reconocer que la tradición marxista se compone de tres elementos: “La crítica del capitalismo, el análisis de clase y una visión normativa más allá del capitalismo" (Olin Wright, en Gayo y Cerda, 2012, p. 125). Ahora bien, la caracterización de Olin Wright desatiende al motor transformativo y en menor medida al motor crítico. El autor no toma en consideración que la "visión normativa más allá del capitalismo" es el resultante de un momento determinado de combustión del motor transformativo y que dicho motor integra una política de 
masas orientada por un principio estratégico. La idea de un "mas allá del capitalismo" no se puede hipostasiar como un horizonte de expectativas predeterminado, ni tampoco se puede suponer que el horizonte de expectativas de Marx respecto a tal movimiento de superación podría asemejarse al que se presenta en la actualidad para una sociología moderna de izquierdas. Una visión trimotor también se hace presente en las definiciones del politólogo de la NYU Bertell Ollman. El autor define el marxismo como "una combinación inusual, posiblemente única, entre ciencia, crítica, visión y receta para la revolución" (Ollman, 2003, p. 115). Para Ollman tales elementos están usualmente tan entrelazados y son tan interdependientes que resulta muy difícil separarlos. Ahora bien, aquí el autor cae en un error bastante usual entre los intelectuales marxistas: no distingue los diferentes niveles de abstracción que componen el motor transformativo marxiano. Tal indistinción lo lleva a confundir la forma-progresión del motor transformativo respecto a su concreción socio-histórica específica en una teoría de la revolución (sobre este tema ver el punto 4 del texto). Ahora bien, una de los conceptualizaciones mejor logradas del proyecto trimotor marxiano es la que ofrece el ya fallecido filósofo español Adolfo Sánchez Vázquez, exiliado en México. Sánchez Vázquez sostendrá que la empresa marxiana es un "proyecto de transformación del mundo realmente existente, a partir de su crítica y de su interpretación o conocimiento" (Sánchez Vázquez, 2004 , p. 4). En cualquier caso tal afirmación merecería corregirse en dos aspectos: no hay equivalencia entre interpretación y conocimiento en la práctica teórica de Marx, ni la crítica precede al conocimiento científico. Finalmente, una combinación virtuosa y aplicada de los tres motores marxianos se puede observar en el concepto de Capitalist Landnahme que desarrolla Klaus Dörre. El sociólogo alemán parte del registro original de un movimiento socio-histórico de expropiación capitalista y a partir de ello despliega diferentes programáticas de acción concreta (ver Dörre, 2015; 2016). 
Entre otros aspectos, la dinámica trimotor del pensamiento de Marx demuestra la existencia de una relación de inmanencia entre razón científica, ética crítica y voluntad transformadora. Se trataría de tres elementos que hay que dotar de contenidos y constructos teóricos concretos para cada momento histórico. Al definir su perspectiva como una "revolución permanente" (Marx, 1960, p. 221), Marx está aludiendo a un dinamismo racionalista de carácter científico, crítico y político no reducible a una teoría política específica. El reconocimiento de la motorización triádica permite indicar que es el modo de resolución contextual de dicha combinatoria el que define para el autor el horizonte de expectativas y los contenidos del programa político para la transformación social. ¿Esto qué significa en términos más concretos? Pues que en el dispositivo teórico marxiano no opera en primera instancia una esencia anticapitalista ni poscapitalista. La emanación poscapitalista, en las formas prototípicas del comunismo o del socialismo, es producto de una resolución específica de la ecuación científico-crítica-transformadora para una situación socio-histórica concreta. Una de las desorientaciones centrales de la Última Izquierda y de una fracción considerable del marxismo contemporáneo se produce por la imposibilidad de entender las relaciones que Marx establece entre los motores señalados. Las confusiones de este sector intelectual también crecen por el desconocimiento de la dinámica que conecta los planos abstractos y concretos de la práctica teórica del sociólogo alemán. 


\section{El motor científico: la innovación permanente}

Al igual que sucede con el conjunto de la teoría social clásica, el elemento número uno de la práctica teórica de Marx es su núcleo científico. La ciencia moderna es la fuerza de propulsión dominante del pensamiento marxiano. Tal constatación nos permite despejar un cúmulo de prejuicios abonados y acumulados por la Última Izquierda. Desde principios de la década de 1980 el marxismo y el pos-marxismo contemporáneo, al menos en América Latina, se ocuparon de desactivar el motor científico marxiano, alimentando con ello un escepticismo y un irracionalismo que desde entonces no ha hecho más que crecer. El método marxiano es un método de conocimiento clásico en tanto se orienta a la dilucidación científica y a la pretensión de control científico-técnico del movimiento socio-histórico. Se trata de un proyecto laborioso y creativo que guarda un interés colectivista por incidir en la prefiguración del destino de las sociedades. Dicho método no equivale en primera instancia a una interpretación económica de la Historia, como sugiere Schumpeter (2008, p. 67), sino a un conjunto de principios en constante revisión a partir de los cuales el sociólogo alemán edifica y proyecta una teoría de la forma y del movimiento de las cosas, de los sujetos y de las ideas. Contra aquel prejuicio extendido que concibe la ciencia marxiana como garante de un auspicioso futuro poscapitalista, el motor científico marxiano sólo garantiza un compromiso con una pretensión explicativa y posteriormente transformativa de los procesos socio-históricos. Tal racionalismo integral de ningún modo suprime el reconocimiento del carácter contingente de los procesos socio-históricos. 
A diferencia del proyecto frankfurtiano, el núcleo racional marxiano fija una relación de inmanencia entre crítica y ciencia instrumental habilitando un momento positivo para la aprehensión del mundo. Marx dirá al respecto, en uno de sus fragmentos más ilustrativos, que "allí donde termina la especulación en la vida real, comienza también la ciencia real y positiva, la exposición de la acción práctica y del proceso práctico de desarrollo de los hombres" (Marx y Engels, 1969, p. 130). En cualquier caso, siendo fiel al proyecto científico del sociólogo alemán, lo correcto sería señalar que si la realidad social cambia, cada uno de los motores de la práctica teórica marxiana necesita ser revisado y reajustado. Dicho reajuste lo exige el motor científico y se define en el marco de la relación que cada uno de los motores establece con los demás para cada momento. Desactivar la lógica de actualización continua del motor científico lleva irremediablemente a profundizar la obsolescencia y el error.

Marx estaba completamente persuadido de que sin ciencia no hay futuro mejor y de que no hay desarrollo del motor científico de la práctica teórica sin el apego a un imperativo de innovación permanente que desacredita toda forma política predeterminada. Un supuesto que se deduce con facilidad del principio de actualización comentado es que no hay horizontes utópicos estables ni imperecederos. Marx estaría dispuesto a sostener que en la medida que existan expectativas reales de movilización social de masas y de realización práctica de sociedades superiores, se hace necesario procesar metódicamente las novedades estructurantes del mundo social y ajustar los ideales propios en función de los ideales del conjunto de la sociedad. La vigilancia sociológica o científico-social de la proyección ético-política es un 
rasgo constitutivo de la práctica teórica marxiana. Aludiendo al nexo clásico entre política y economía, el sociólogo alemán dirá que "la observación empírica tiene necesariamente que poner de relieve en cada caso concreto, empíricamente y sin ninguna clase de falsificación, la trabazón existente entre la organización social y política y la producción" (Marx y Engels, 1969, p. 90). El motor de la ciencia para Marx no es el interés político, menos aún el político-partidario, sino un tipo de voluntad de saber que podríamos llamar desinteresada, en tanto no está determinada por apetencias políticas y en tanto desborda todo particularismo. En las palabras siempre astutas del sociólogo alemán, se trataría de "entender la ciencia como conocimiento sin más interés que el pensamiento desinteresado" (Marx, 2011, p. 10). Más adelante veremos como la explicación científica es la base de la prognosis social y como el poder de anticipación que anida en la razón prospectiva es el punto de partida para una estrategia exitosa de cambio político.

\section{El motor crítico: la crítica y lo crítico I-II}

El motor crítico de Marx remite, en primera instancia, a la dimensión moral de su práctica teórica conformada a partir de una ética igualitaria. De este modo, en su núcleo íntimo, es en primera instancia una crítica a la desigualdad social y no una crítica al capitalismo. Cuando el sociólogo alemán indica que la tónica de la crítica es la denuncia, y asimismo que la crítica es una forma de indignación o de respuesta al avergonzamiento (Marx, 1976, p. 53), está aludiendo en un sentido restringido al núcleo moral de su crítica. La equivalencia que se puede establecer entre crítica marxiana y crítica del capitalismo no es abstracta sino concreta. 
Tal equivalencia se produce a partir de reconocer desde un horizonte de visibilidad determinado que el capitalismo no sólo es genéricamente un productor de desigualdad social sino que lo es en concreto a partir de un registro comparativo con las demás formas de organización socio-económicas existentes o con probabilidades ciertas de existir en el corto/mediano plazo.

Ahora bien, si el núcleo crítico del pensamiento marxiano se asocia a una fuerza moral sujeta a una parametrización igualitaria, no hay que perder de vista que éste se va conformando en el movimiento triádico de su práctica teórica general. La noción de crítica de Marx, tal como la entiendo, es una fuerza racionalista que atraviesa como una flecha los tres motores comentados definiendo tres engranajes que en su realidad operativa son dinamizados por el motor científico: me refiero a lo crítico I (racional-científico), la crítica (igualdad/desigualdad) y lo crítico II (transformativo). El motor crítico como un todo es el que indica de forma más sensible cómo se procesa la relación entre la objetividad y la toma de partido y, por lo tanto, el que expresa si hay algún tipo de primacía del engranaje científico o del engranaje político en la construcción de la crítica. En la crítica marxiana se puede observar, como en ningún otro elemento, las huellas de la pugna entre los dos engranajes mencionados (lo crítico I y II). Si el motor de la crítica, tal como señalé, remite a un rechazo moral más o menos indignado respecto a una situación de desigualdad estructural, los dos momentos de lo crítico (I y II) se asocian a dos parámetros de relevancia. Lo crítico I es el engranaje que apunta al reconocimiento de los aspectos claves que hay que conocer para poder ofrecer una explicación sintético-general y plausible de los procesos socio-históricos en curso. Si la crítica de la Última 
Izquierda ha devenido inocua e intrascendente es porque en primera instancia dejó de atender a lo crítico I de la práctica teórica de Marx.

Por su parte, lo crítico II se refiere a los aspectos claves que hay que conocer sobre el adversario y a los movimientos claves que hay que hacer para vencer al primero y para transformar la realidad social anteriormente explicada y parcialmente negada. Los tres momentos señalados (la crítica, lo crítico I y lo crítico II) forman el concepto general de crítica del sociólogo alemán y es a partir de tal forma compuesta e inestable que se debería interpretar la afirmación de que la teoría social de Marx es una teoría crítica.

Si el engranaje fundante de la crítica es moral, la crítica concreta como un todo, que se desenvuelve como una crítica sociológica, es una fuerza de base científica y con orientación transformativa. El movimiento de la crítica se eleva a partir de un espiral de vigilancia permanente de cada uno de los engranajes respecto a los demás. La crítica sería en cierto modo, como señala Walter Benjamín, una cuestión de "justa distancia" (Benjamin, 1955, p. 76), si por ello entendemos una pretensión de combinación equilibrada en el procesamiento de una serie de elementos contradictorios. Es el engranaje científico de la crítica y no su engranaje moral el que define el sentido de la radicalidad de la crítica. Esto es comúnmente malintepretado en el pensamiento crítico contemporáneo, proclive a reducir la crítica marxiana al engranaje de la crítica. El hecho de que la crítica marxiana tenga un engranaje político (lo crítico II), esto es, que tenga pretensiones de transformación social, pone a Marx en el aprieto de tener que concebir la crítica sin perder de vista la necesidad de derrotar al 
adversario en el juego social de apropiación en el que se encuentra inmerso. La actuación de este componente político de la crítica se evidencia cuando el autor señala que "la crítica tiene por objetivo a un "enemigo" al que busca aniquilar" (Marx, 2004, p. 53). El engranaje político vuelve a relucir cuando Marx reconoce que la crítica "no cierra su camino en ella misma, sino que se extiende hacia los problemas para cuya solución no existe más que un medio: la práctica" (Marx, 1976, p. 61). Ahora bien, como vengo señalando, ello de ningún modo significa que tal engranaje político determina la forma y el movimiento general de la crítica. Por el contrario, tal imbricación nos alerta de que no hay una escisión en la teoría, al interior del concepto de crítica, entre descubrimiento científico, ética igualitaria y política transformadora de masas. Una fracción considerable del pensamiento social de izquierdas a nivel global, incluyendo la Última Izquierda, generó una retracción tectónica del concepto marxiano de crítica, al punto de desentenderse por completo de los engranajes científico y político de la noción (lo crítico I y lo crítico II). De tal modo, la crítica se redujo a una crítica moral de toda dominación, cargada de irracionalidad, escepticismo e indignación reactiva.

\section{El motor transformativo: forma-activación, forma-progresión y forma-superación}

La transformación social para Marx conlleva una pretensión de trastocamiento estructural de las relaciones de apropiación existentes en un espacio y tiempo determinado. Dicha alteración se orienta a la creación de una nueva forma de organización social para ese mismo arreglo espacio-temporal que permita la 
expansión de un proceso material de igualación social. La pretensión de cambio socio-estructural de Marx integra una solución provisoria a tres problemas que se enlazan de modo inmanente en un mismo proceso social: la cuestión de cómo activar la ruptura del orden social existente, la cuestión de cómo progresar hacia la construcción de uno nuevo, y, finalmente, la cuestión de cuál nuevo orden social sería deseable y posible de edificarse. El primer problema atañe a lo que denomino forma-activación, el segundo a la forma-progresión y el tercero a la forma-superación. Se trata de tres formas abstractas y metahistóricas que conforman el motor transformativo de la práctica teórica de Marx. Cada una de estas formas se concretiza a partir de una teoría socio-histórica específica, en un proceso intelectual de regeneración dialéctica entre lo abstracto y lo concreto. La incapacidad de diferenciar ambos niveles del motor transformativo explica muchos de los grandes errores interpretativos cometidos por la Última Izquierda.

Aquí simplemente presentaré cada una de dichas formas. La forma-activación es un registro relacional de las voluntades, las capacidades y las posibilidades efectivas de avanzar sobre las posiciones y los proyectos de aquellos actores que se pretende desplazar o minimizar. La forma-activación marxiana se concentra en el esclarecimiento de la modalidad de acción y de interacción social que se pone en juego y que se debería poner en juego en un escenario más auspicioso. En términos esquemáticos, la teoría de la lucha de clases es la teoría socio-histórica correspondiente a la forma-activación del motor transformativo marxiano.

La forma-progresión, por su parte, es un registro procesual de las posibilidades efectivas y combinadas de destrucción estructural 
de lo existente y de creación de nuevas estructuras sociales. Si la forma-activación se pregunta por el modo de ganar una batalla, la forma-progresión se pregunta por las formas de ganar una guerra a partir de una sucesión de batallas. Si la forma-activación alude a una modalidad de acción y de interacción, la forma-progresión atiende a una modalidad de cambio. Si el tiempo dominante de la forma-activación es el futuro-inmediato, la forma-progresión se resuelve entre el tiempo inmediato, el tiempo próximo y el tiempo remoto, con epicentro en el tiempo próximo. La teoría socio-histórica que acompaña a la forma-progresión marxiana es la teoría de la revolución. Para Marx se trata de la conceptualización de una modalidad de cambio específica y no la expresión de todo modo de cambio socio-estructural posible. Si la forma-progresión sigue siendo totalmente válida en la actualidad, la teoría de la revolución como vía de cambio socio-estructural ha caído en una completa obsolescencia. El error teórico central de la Última Izquierda en este punto vuelve a tener que ver con la incapacidad de distinguir entre ambos planos de abstracción. Desde principios de la década de 1980, en el marco de la última declaración de crisis del marxismo, se argumentó que la invalidez de la teoría de la revolución condenaba a la obsolescencia al motor transformativo de Marx. La reconstrucción de la práctica teórica del sociólogo alemán en los términos del presente trabajo permite evidenciar las deficiencias de dicha interpretación. Sería más plausible señalar que para Marx la interacción entre el motor científico y el motor transformativo es la que construye y actualiza el marco sociológico y el modo de cambio posible para la acción política de masas. De este modo, contra la Última Izquierda, diré que la puesta en marcha de la dinámica trimotor de la práctica teórica marxiana 
se encargaría por si misma de descartar hoy la teoría marxiana de la revolución.

Finalmente, la forma-superación es una construcción ideal regulada por la forma-activación y la forma-progresión, siendo a la vez reguladora de éstas últimas. De esta manera, si la forma-activación y la forma-progresión obedecen para Marx a principios tácticos y estratégicos respectivamente, la forma-superación es una modalidad de ordenamiento ideal que actúa como horizonte de expectativas último del motor transformativo. Ya señalé que para Marx la forma-activación se concreta en la lucha de clases y la forma-progresión a partir de una teoría de la revolución. Falta entonces agregar que la forma-superación se concretiza a partir de un ideal societal socialista o comunista. Para Marx, el tiempo dominante de la forma-superación no es el futuro inmediato (forma-activación) ni el futuro próximo (forma-progresión) sino un tiempo futuro que se define en la tensión entre el tiempo próximo y el tiempo remoto o de largo plazo, sin un epicentro pre-determinado.

Las diferentes temporalidades futuras que se eslabonan al interior del motor transformativo de Marx se entrelazan, a su vez, con la temporalidad social general del motor científico de su práctica teórica. Si los futuros inmediato, próximo y remoto pueden ser conceptualizados en términos realistas por el sociólogo alemán es porque se inscriben en una temporalidad total que integra el pasado, el presente y el futuro. De este modo, es constatable como el motor transformativo de Marx no puede funcionar prescindiendo del principio procesual del motor científico. De lo que se trata para el autor -en esto acierta García Linera- es de tornear el proceso socio-evolutivo de la humanidad desde un arreglo 
espacio-temporal determinado (García Linera, 2017). La irrupción y las posibilidades de creación de lo nuevo en la historia se conciben en todos los casos para Marx como una emergencia en y desde la realidad social existente. Esto básicamente significa que no hay forma de transformar la sociedad sin atender al modo en que se despliegan en un registro diacrónico las lógicas de reproducción o de continuidad social. El movimiento dialéctico entre los tres motores de Marx permite observar que el ideal societal no se decreta a partir de un golpe de autodeterminación sino que se nutre y se limita a partir del output que arrojan el motor científico y el motor crítico.

Observado desde el núcleo transformativo, la operación conjunta de estos tres motores se expresa paradigmáticamente en la conocida apelación de Marx a un "movimiento real, que anula y supe$r a$ al estado de cosas actual" ${ }^{5}$ (Marx y Engels, 1969, p. 37). En esta referencia "lo real" representa el momento de apropiación racional-científica, la anulación es un modo de expresión de la crítica y la superación es la lógica rectora del motor transformativo. Es muy importante tomarse en serio esta noción de superación o de trascendencia de lo dado ya que es el concepto más exacto que ofrece el sociólogo alemán para dar cuenta de la forma procesual a partir de la cual se activa el motor transformativo. Volviendo al paso de lo abstracto a lo concreto se observa que la lucha de clases, la programática revolucionaria y el horizonte de expectativas comunista/socialista constituyen los componentes político-concretos centrales de la teoría social de Marx, y, en tanto componentes concretos, están indefectiblemente sujetos a cierto grado

\section{Las cursivas son mías.}


de obsolescencia. En este punto, lo relevante de la diferenciación entre un plano abstracto de las formas y un plano concreto de las teorías específicas es que permite observar en qué medida y de qué modo es afectado el dispositivo sociológico de Marx en su movimiento teórico de destrucción y de creación permanente de elementos.

\section{A modo de conclusión}

Si bien no hay concepto fuera de su sociedad y todo concepto está potencialmente sujeto a cambios, las tres formas mencionadas que componen el plano abstracto y metahistórico del motor transformativo de Marx continúan siendo completamente válidas y pertinentes en la actualidad para actualizar un proyecto intelectual moderno de izquierdas. No se puede decir lo mismo de las tres teorías específicas que conforman el momento concreto del motor transformativo. Me refiero a la teoría de la lucha de clases, a la teoría de la revolución política proletaria y a la teoría de los modos de producción socialista y/o comunista. Éste no es el espacio para indicar al detalle qué está muerto y qué está vivo de cada uno de estos últimos constructos. Para el caso, basta con señalar que todos ellos revisten en la actualidad niveles significativos de inadecuación.

A modo de síntesis, creo que no hay que perder de vista que el vector de la teoría de Marx, como toda teoría clásica, va de lo racional-científico a lo político o de lo racional-científico a lo transformativo. La forma-activación, la forma-progresión y la forma-superación se definen para nuestro autor a partir de la supeditación al núcleo racional-científico de su teoría, así como a 
partir de la comunicación con su núcleo crítico. La idea marxiana de transformación social está viva en tanto es concebida como un proceso de trastocamiento y de transición estructural que se proyecta, se desprende y se imagina a partir de un principio socio-evolutivo o de una teoría del movimiento de lo real. La sujeción del motor transformativo al motor científico es el antídoto que ofrece la teoría social de Marx contra el utopismo y contra todo intento de reproducir las soluciones prácticas ofrecidas por el autor para cambiar el mundo hace más de un siglo.

\section{Referencias}

Badiou, A. (2007). Le Reveil de l'Histoire. Paris: Éditions Lignes [En español: (2012). El despertar de la Historia. Buenos Aires: Nueva Visión]. Benjamin, W. (2005[1955]). Dirección única. Madrid: Alfaguara.

Bidet, J. (2005). What is Marxism today? [Lecture at Fudan University], Shanghai.

Burawoy, M.; Olin Wright, E. (2000). Sociological Marxism. In: Turner, Jonathan (2001), Handbook of sociological theory. New York: Springer.

Burawoy, M. (June 2003). For a Sociological Marxism: The Complementary Convergence of Antonio Gramsci and Karl Polanyi. Politics \& Society, 31(2), 193-261.

Dörre, K. (2015). Social Capitalism and Crisis: From the Internal to the External Landnahme. In: Dörre, Klaus; Lessenich, Stephan; Rosa, Hartmut (Hrsg.) (2015). Sociology - Capitalism - Critique, 247-277. London/New York: Verso.

Dörre, K. (2016). The Limits of Landnahme: Capitalism will not die by itself, but it can be overcome. En: Dellheim, Judith/Wolf, Frieder Otto 
(Hrsg.). Europe - What's left? Working on the strategies (pp. 60-77). Brüssel: Rosa Luxemburg Stiftung Büro Brüssel.

Eagleton, T. (2011). Why Marx Was Right. New Haven: Yale University Press. [En español: (2011). Por qué Marx tenía razón. Barcelona: Península].

Febbro, E. (4 de mayo de 2012). Entrevista con Alain Badiou. Todo lo que necesitas es amor. Página 12.

García Linera, Á. (2017). ¿Qué es una revolución? De la revolución de 1917 a la revolución de nuestro tiempo. La Paz:Vicepresidencia del Estado Plurinacional de Bolivia.

Gayo, M.; Cerda, A. (2012). "Entrevista a Erik Olin Wright”. Revista de Sociología, $\mathrm{N}^{\mathrm{o}} 27,123-137$.

Lewkowicz, I. noviembre del 2000). "Marxismo: Legado y Herencia”. Revista Gradocero, 01 (01), Rosario.

Marx, K.; Engels, F. (1969). Die deutsche Ideologie. Berlin/DDR: Dietz Verlag, 1969. [En español:(1985). La ideología alemana. Buenos Aires: Pueblos Unidos].

Marx, K. (1976). Zur Kritik der Hegelschen Rechts-Philosophie. Berlin: Dietz Verlag [En español: (2004). Crítica de la filosofía del derecho de Hegel. Buenos Aires: Ediciones del Signo].

Marx, K. (2011). Das Kapital. Kritik der politischen Ökonomie. Buch 1. Sttutgart: Alfred Kröner Verlag [En español: (2002). El Capital. Crítica de la economía política, Tomo I. El proceso de producción del capital. Buenos Aires: Siglo XXI].

Marx, K. (1960). Die Klassenkämpfe in Frankreich 1848 bis 1850. Berlin/ DDR: Dietz Verlag. [En español: (2005). Las luchas de clases en Francia de 1848 a 1850. Buenos Aires: Luxemburg].

Musto, M. (2012), Introduction. En Musto, Marcello (ed.), Marx for today. USA-Canada: Routledge. 
Ollman, B. (2003). Dance of the Dialectic: Steps in Marx's Method. USA: University of Illinois Press.

Ríos, A.; Díaz, A. (noviembre de 2013). El Marxismo es mucho más que un método crítico. Entrevista con Terry Eagleton. Ideas de Izquierda, 5 , 37-39.

Sánchez Vázquez, A. (16 de septiembre de 2004), ¿Se puede ser marxista hoy? [Discurso de Investidura, Doctorado Honoris Causa]. Cuba: Universidad de La Habana.

Schumpeter, J. A. (2008). Capitalism, Socialism, and Democracy. Third Edition. New York: Harper Perrenial [En español:(1996). Capitalismo, socialismo y democracia. Tomo I. Barcelona: Folio].

Žižek, S. (2008). In Defense of Lost Causes. London: Verso [En español: (2008). En defensa de causas perdidas. Madrid: Akal]. 